\title{
Evaluation of Post-Stroke Depression in Patients with Cerebral Vascular Disorder
}

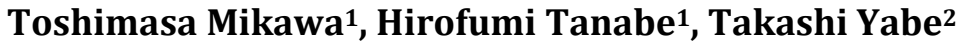 \\ ${ }^{1}$ Department of Health Sciences, Shonan University of Medical Sciences, Yokohama-shi, Kanagawa-ken, Japan \\ ${ }^{2}$ Shonan Tobu General Hospital, Chigasaki-shi, Kanagawa-ken, Japan \\ Email: toshimasa.mikawa@sums.ac.jp, hirofumi.tanabe@sums.ac.jp
}

How to cite this paper: Mikawa, T., Tanabe, H., \& Yabe, T. (2020). Evaluation of Post-Stroke Depression in Patients with Cerebral Vascular Disorder. Open Journal of Depression, 9, 86-94. https://doi.org/10.4236/ojd.2020.94008

Received: July 22, 2020

Accepted: November 24, 2020

Published: November 27, 2020

Copyright (c) 2020 by author(s) and Scientific Research Publishing Inc. This work is licensed under the Creative Commons Attribution International License (CC BY 4.0).

http://creativecommons.org/licenses/by/4.0/

\section{Open Access}

\begin{abstract}
During the period effective rehabilitation and occurrence of depressive symptoms overlap in patients with cerebral vascular disorder. This study was conducted to clarify the medical professionals' responses to such cases by determining the state of depression. This study involved qualitative analysis of free response questionnaire data. The study includes patients with a history of cerebral vascular disorder. The questionnaire authors reviewed all questions intended for free response before inclusion in the questionnaire. Questionnaires were handed off to patients between May 15 and July 15, allowing them 2 weeks to reply. The deadline for return was July 31, 2019. The recovery rate was $64.1 \%$. A total of 245 words and 21 subcategories were extracted. Major categories of One's own feelings (44.9\%), Interaction with people (32.2\%), and Uncertainty about the future (22.9\%) were identified. Because the recovery of physical functions can aid in the recovery from depressive symptoms, medical professionals must be indirectly involved in the recovery from depressive symptoms.
\end{abstract}

\section{Keywords}

Post-Stroke Depression, Rehabilitation, Contents Analysis

\section{Introduction}

The incidence (lifetime prevalence) of depression and post-stroke depression (PSD) in Japan is reported to be 6.6\% (Kessler \& Bromet, 2013) and 29\% (Ayerbe, Ayis, Wolfe, \& Rudd, 2013), respectively-a markedly higher rate than that for general major depression. Although no particular diagnostic standards exist for PSD, an investigation by Lipsey, Spencer, Rabins, \& Robinson (1986) found no clear differences compared to depression. Moreover, the researchers 
found that the $10^{\text {th }}$ revision of the International Statistical Classification of Diseases and Related Health Problems (World Health Organization, 1992) as well as the Diagnostic and Statistical Manual of Mental Disorders-5 (DSM-5) (American Psychiatric Association, 2013) were used to diagnose depression. An investigation into the frequency of depression among patients undergoing orthopedic surgery corresponded to the physical function of stroke patients, finding that the incidence of depression was only $10 \%$ among patients undergoing orthopedic surgery but 45\% among stroke patients (Folstein, Maiberger, \& McHugh, 1977). This suggests that direct brain damage may be a factor in PSD. Still, patients exhibiting endogenous depression symptoms following cerebral vascular disorder are currently diagnosed with PSD (Osada, Muraoka, \& Liu, 2007).

Although rehabilitation for stroke has been reported to provide gradual recovery up to 6 months after onset, PSD symptoms may be observed even 12 months after stroke in $22 \%$ of patients (Ostir, Berges, Ottenbacher, \& Ottenbacher, 2011). Thus, PSD symptoms represent a missed effective rehabilitation period, resulting in delayed functional recovery and decreased activity in daily life (ADL) (Tateno \& Robinson, 2002). Therapeutic exercise has been indicated as effective in preventing or easing depressive symptoms starting from the subacute phase to the chronic phase during recovery from depression (Duncan, Lai, \& Keighley, 2000). Since the functional status of the patient rapidly improves immediately after onset, it is best to focus on treatment of PSD (Ahn, Lee, Jeong, Kim, \& Park, 2015). However, epidemiological research in Japan has indicated that when a depressive state is present, only $41.7 \%$ of patients seek medical care. This suggests that more than half of patients are left untreated (Kawakami, 2016). The period during which cerebral vascular disorder rehabilitation is effective remains controversial, and during the period depressive symptoms appear overlap. We therefore maintain that if status at onset can be determined, treatment should be implemented within the effective rehabilitation window, thereby avoiding any reductions in ADL. This study aims to clarify post-stroke state while focusing on depression and response to PSD, which affect the implementation of rehabilitation in patients who suffer from cerebral vascular disease.

\section{Material and Methods}

\subsection{Design}

This study involved qualitative analysis of free response questionnaire data.

\subsection{Participants}

The study includes patients with a history of cerebral vascular disorder. Those with clear signs of dementia, suspected higher brain dysfunction, or those who required a long time to understand the research project were excluded from the study. Sample size was determined by observing saturation while categorizing results. 
Patients living in local communities were considered ideal candidates and patients involved in support workshops on therapeutic techniques were also included. Therapeutic procedure workshop and support workshop representatives were provided with pamphlets clearly explaining the purpose of the study. After providing oral and written explanations, consent was obtained to distribute questionnaires during the workshops. The pamphlets also indicated that consent could be withdrawn at any time before the end of the study.

\subsection{Data Collection Procedures}

The questionnaire authors reviewed all questions intended for free response before inclusion in the questionnaire. Space was provided in the questionnaire for free responses regarding depressive symptoms at the time of stroke, and a question was included regarding depressive symptoms. The question asks: "Please describe your feelings around the time when you became ill." An explanation of the present study, a form requesting study participation, and an envelope for returning the questionnaire were also distributed. Questionnaires were handed off to patients between May 15 and July 15, allowing them 2 weeks to reply. The deadline for return was July 31, 2019.

Patients were asked to fill in the answers themselves. However, if they found it difficult to write, they were allowed to use a text generator or similar software to print their answers on paper.

\subsection{Data Analysis}

Berelson (1952) content analysis was performed as follows:

1) Based on the recovered questionnaires, any answers that had not been filled in or had been marked "difficult to respond" were considered non-responses and excluded from data analysis.

2) For each piece of data, we converted responses to each question into contextual units and then broke them down into record units to calculate their frequency of appearance.

3) The segmented record units were extracted into similar record unit groups and named based on the similarity in their elements.

4) Similar record unit groups were then extracted and labeled as categories based on their similarity.

5) To increase the reliability of category extraction and naming, two occupational therapists with at least 10 years of experience as well as experience in qualitative research were asked to extract the categories from similar record unit groups. Cohen's kappa coefficient was calculated from the categorized results.

\subsection{Ethical Considerations}

Because this study was conducted using an anonymous self-administered questionnaire, no consent form was required (Figure 1). The fact that data would not be used for any purposes other than this study was clearly stated in the explanation form. Furthermore, we have specified that the data will be made available in 
medical Journals and have requested response only in cases of participant agreement. Moreover, it was stated that filling out the questionnaire and returning it would indicate consent to participate in this study, and that response revocation would be impossible given anonymous data encoding shortly following delivery to researchers.

This study was approved by the Institutional Review Board of Shonan University of Medical Sciences (approved on April 16, 2019; approval no. 19-002).

\section{Results}

\subsection{Recovery Rate}

In total, 64 questionnaires were distributed, and 41 questionnaires were returned. There were no blank questionnaires or questionnaires in which responses clearly differed from the questions. Thus, there were 0 non-responses and 41 questionnaires were eligible for analysis. The recovery rate was calculated as $64.1 \%$. For this calculation, the number of distributed questionnaires was set as the denominator and the number of recovered questionnaires as the numerator.

\subsection{Analysis Targets}

In total, 245 words were extracted from the recovered responses. From the analysis of these words, we identified 21 subcategories, from which three major categories were extracted (Table 1). Hereinafter, major categories are described in italics, subcategories in brackets, and phrases in quotation marks.

Survey for post stroke Depression
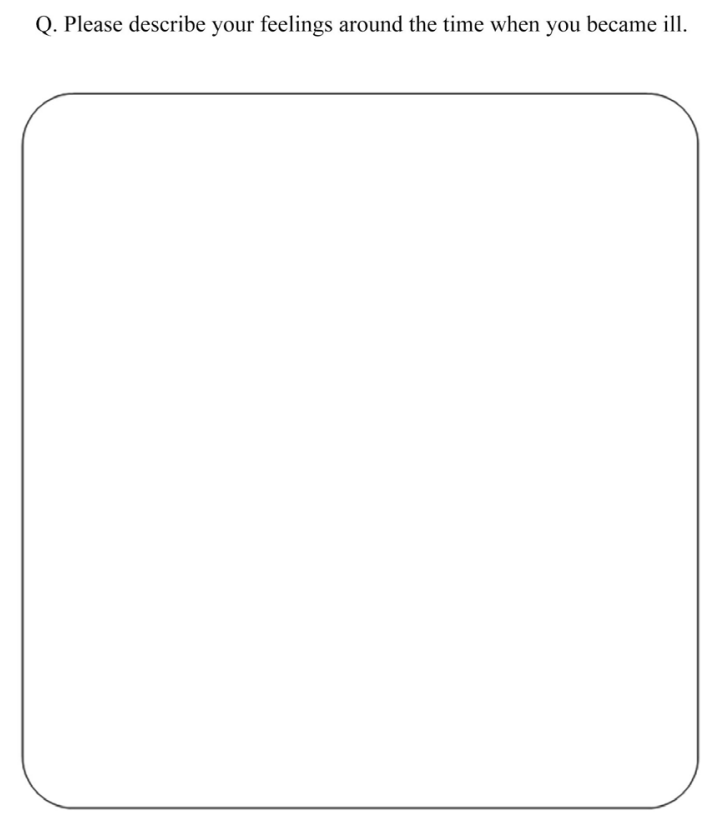

Figure 1. An open-ended survey of post stroke depression. 
Table 1. Overview of categories.

\begin{tabular}{|c|c|c|c|}
\hline \multirow{10}{*}{$\begin{array}{l}\text { One's own } \\
\text { feelings }\end{array}$} & \multirow{10}{*}{$\begin{array}{l}110 \\
(44.9 \%)\end{array}$} & Bravely facing illness with a positive attitude & $24(9.8 \%)$ \\
\hline & & Miserable feelings of having a disability & $23(9.4 \%)$ \\
\hline & & Not being able to enjoy leisure activities & $20(8.1 \%)$ \\
\hline & & Not being able to understand what is happening to oneself & $10(4.1 \%)$ \\
\hline & & Frequency of thinking about one's own death & $8(3.3 \%)$ \\
\hline & & Having no memory of the acute period & $8(3.3 \%)$ \\
\hline & & $\begin{array}{l}\text { Major difference between current situation and situation } \\
\text { before illness }\end{array}$ & $5(2.0 \%)$ \\
\hline & & Opportunities to consider one's reason for existence & $4(1.6 \%)$ \\
\hline & & History of depression & $4(1.6 \%)$ \\
\hline & & Difficulty communicating due to speech impediment & $4(1.6 \%)$ \\
\hline \multirow{7}{*}{$\begin{array}{l}\text { Interaction } \\
\text { with people }\end{array}$} & \multirow{7}{*}{$\begin{array}{l}79 \\
(32.2 \%)\end{array}$} & Medical staff response & $15(6.1 \%)$ \\
\hline & & Words of medical staff & $14(5.7 \%)$ \\
\hline & & Being supported by family and friends & $14(5.7 \%)$ \\
\hline & & Being supported by fellow patients with the same disease & $11(4.5 \%)$ \\
\hline & & Feeling more comfortable alone & $9(3.7 \%)$ \\
\hline & & $\begin{array}{l}\text { Switching from joy to sorrow when comparing oneself } \\
\text { with others }\end{array}$ & $9(3.7 \%)$ \\
\hline & & Recognizing that one is a burden to one's family & $7(2.9 \%)$ \\
\hline \multirow{4}{*}{$\begin{array}{l}\text { Uncertainty } \\
\text { about the } \\
\text { future }\end{array}$} & \multirow{4}{*}{$\begin{array}{l}56 \\
(22.9 \%)\end{array}$} & Uncertainty regarding one's future lifestyle & $22(9.0 \%)$ \\
\hline & & Excessive anticipations for recovery & $14(5.7 \%)$ \\
\hline & & $\begin{array}{l}\text { Stabilized feelings as a result of return to work or } \\
\text { re-employment }\end{array}$ & $13(5.3 \%)$ \\
\hline & & Financial anxiety due to interrupted income & $7(2.9 \%)$ \\
\hline
\end{tabular}

\section{1) One's own feelings (110 (44.9\%))}

This major category was extracted from the following 10 subcategories: [bravely facing illness with a positive attitude (24 (9.8\%))], [miserable feelings of having a disability $(23(9.4 \%))$ ], [not being able to enjoy leisure activities (20 $(8.1 \%))$ ], [not being able to understand what is happening to oneself (10 $(4.1 \%))$ ], [frequency of thinking about one's own death (8 (3.3\%))], [having no memory of the acute period (8 (3.3\%))], [major difference between current situation and situation before illness $(5(2.0 \%))$ ], [opportunities to consider one's reason for existence $(4(1.6 \%))$ ], [history of depression $(4(1.6 \%))$ ], and [difficulty communicating due to speech impediment $(4(1.6 \%))$ ]. Of the feelings experienced by patients due to their illness, this major category comprised subcategories in which patients described depressed or stagnated feelings. The number of recorded units was 110 , accounting for $44.9 \%$, making this the major category with the most recorded units.

2) Interaction with people (79 (32.2\%)) 
This major category was extracted from the following seven subcategories: [medical staff response (15 (6.1\%))], [medical staff remarks (14 (5.7\%))], [being supported by family and friends $(14(5.7 \%))$ ], [being supported by fellow patients with the same disease $(11(4.5 \%))$ ], [feeling more comfortable alone $(9$ $(3.7 \%))$ ], [switching from joy to sorrow when comparing oneself with others (9 (3.7\%))], and [recognizing that one is a burden to one's family $(7(2.9 \%))]$. This major category further comprised five subcategories describing the interaction with others including both medical personnel and friends and included 79 record units, accounting for $32.2 \%$.

3) Uncertainty about the future (56 (22.9\%))

This major category was extracted from the following four subcategories: [uncertainty regarding one's future lifestyle (22 (9.0\%))], [excessive expectations for recovery $(14(5.7 \%))$ ], [stabilized feelings as a result of return to work or re-employment $(13(5.3 \%))$ ], and [financial anxiety due to interrupted income (7 $(2.9 \%))]$. It comprised subcategories describing thoughts or anxiety about the future and included 56 record units, accounting for $22.9 \%$.

\subsection{Category Name Concordance Rate}

Cohen's kappa coefficient was calculated to be 0.692 , and agreement was determined to be satisfactory.

\section{Discussion}

In this study, we examined the feelings of stroke victims when they become ill. As a result, feelings of stroke victims were categorized as One's own feelings, Interaction with people, and Uncertainty about the future. One's own feelings was further categorized as [Not being able to enjoy leisure activities], [Frequency of thinking about one's own death], and [Opportunities to consider one's reason for existence]. Symptoms of depression cited in the DSM-V (American Psychiatric Association, 2013) include diminished interest, decreased appetite, insomnia or excessive sleeping, psychomotor restlessness or inhibition, fatigue, feelings of guilt, difficulty in making decisions, and suicidal thoughts. Our study found many symptoms that coincide with a diagnosis of depression, and individuals were often aware of their depression. Cerebral vascular disorder requires long-term care in $16.6 \%$ of Japanese patients, making it the second most common reason for long-term care following dementia. Moreover, this number is increasing within Japan. Stroke is a chronic disease that is likely to involve a nursing care situation, and the number of such cases indicates that it is widely recognized by the public. The unfamiliar experience of not being able to move half of the body is shocking, and it is easy to see how depression may result.

The subcategory [miserable feelings of having a disability] included the expressions "Having to constantly say 'excuse me' and 'thank you'." Japanese medical professionals often hear expressions such as "excuse me" and "thank you" in our daily interactions, and they rarely attempt to understand the mean- 
ing behind such words. Moreover, it is true that people with disabilities tend to use phrases like "excuse me" and "thank you" often. Japanese clinicians should be mindful that when patients use such expressions, they may be expressing sadness.

The subcategory [Frequently thinking about one's own death] included eight instances, as there were many cases of considering one's own death due to morbidity. Reasons for a $49.2 \%$ suicide rate in Japan include health problems (Jorgren, Nakayama, Raaschou, Vive-Larsen, Stoier, \& Olsen, 1995) such as physical impairment in $31.3 \%$ of cases and depression in $40.0 \%$ of cases. Indeed, PSD strongly increases the risk of suicide. However, [bravely facing illness with a positive attitude] was the most common subcategory extracted from participant responses. Even when depression followed cerebrovascular disease, a sense of not losing to disease and a focus on a new life style were mentioned.

[Interaction with people] was the second most common subcategory. Immediately after the onset of symptoms, [Interaction with people] seemed to be calming but also stressful. There were many expressions indicating this feeling not only towards family and friends, but also towards medical staff. Responses were largely positive and included supportive expressions, though some responses indicated that the individual felt they had become a burden, displayed an intent to self-punish on behalf of their family. Many responses indicated that patients had been subject to abusive language and disparaging comments by medical staff. Because hospital staff are involved in all aspects of the patients' life from general needs to hospital treatment, where patients spend much of their time, hospital staff may have an equal or greater impact on a patient's life than family members. We need medical staff to take into account the extent of their impact on the target patient population while also advancing care by addressing mental faculties and building a reliable relationship at the time of onset.

The subcategory [being alone] can benefit from support of the family and hospital mates, but may lead to a sense of humiliation, so it was included under the major category [Interactions with people]. By comparing their health to that of family and friends, patients are likely to slip into depression. Some are comforted by the presence of hospital mates, but others find themselves comparing their physical function to that of others. As a result, an individual may experience jealousy if their mate's health is superior, and may feel a sense of superiority if their mate's health is inferior. However, this mode of thinking can itself lead to depression via a sense of self-disgust. Medical staff can help by providing for adequate personal time while also staying close enough to respond when help is needed.

Regarding uncertainty about the future, as suggested by the category I don't understand what has happened to me, individuals have trouble comprehending their new bodily state. However, rehabilitation improves bodily function and can lead to a gradual recovery of stroke symptoms up to six months after onset (Ostir, Berges, Ottenbacher, \& Ottenbacher, 2011). Additionally, the Comprehen- 
sive Survey of Living Conditions (2016) notes functional recovery 12.5 weeks after onset for chronic disease. The stroke recovery curve gradually flattens, and there are a diverse range of symptoms. In other words, the degree and duration of recovery varies from person to person, and comparison with hospital mates makes it difficult to understand one's own state. It is therefore difficult to judge prognosis, which may cause uncertainty about the time of discharge or return to work, and may cause more anxiety in the individual about the future.

Although cerebrovascular disorders are chronic diseases that force people to live with disabilities, many can focus on rebuilding their lives. Our medical staff constantly evaluate patients so as to keep an eye on areas that require support, maintain an ability to immediately respond to an event, and provide medical care in partnership with the patient.

\section{Limitation}

Apathy is similar to depressive symptoms as defined by Marin (1991), specifically a decrease in emotions, pain, and interest. Another study (Starkstein, Fedoroff, Price, Leiguarda, \& Robinson, 1993) investigating stroke patients found signs of apathy in $22.5 \%$ of cases. However, the participants in our study may have found it difficult to answer questions regarding apathy given that there was no clear operational definition included in the questionnaire. Moreover, the survey did not specify the exact post-onset stage, so patients may have answered with respect to everything from shock to adaptation per Cohn (1961) impairment acceptance stages theory. This is assumed to have led to a wide range of responses.

A questionnaire-based survey was conducted for this study, but it would be desirable to conduct a semi-structured interview in the future while remembering to distinguish types of apathy as well as time from onset of symptoms.

\section{Acknowledgements}

The authors would like to thank PTS Group International Company Limited for their assistance in manuscript translation and editing.

\section{Conflicts of Interest}

The authors declare no conflicts of interest regarding the publication of this paper.

\section{References}

Ahn, D. H., Lee, Y. J., Jeong, J. H., Kim, Y. R., \& Park, J. B. (2015). The Effect of Post-Stroke Depression on Rehabilitation Outcome and the Impact of Caregiver Type as a Factor of Post-Stroke Depression. Annals of Rehabilitation Medicine, 39, 74-80. https://doi.org/10.5535/arm.2015.39.1.74

American Psychiatric Association (2013). DSM-5, Diagnostic and Statistical Manual of Mental Disorders (5th ed., pp. 591-644). Washington DC: American Psychiatric Publishing. https://doi.org/10.1176/appi.books.9780890425596

Ayerbe, L., Ayis, S., Wolfe, C. D., \& Rudd, A. G. (2013). Natural History, Predictors and Outcomes of Depression after Stroke, Systematic Review and Meta-Analysis. The Brit- 
ish Journal of Psychiatry, 202, 14-21. https://doi.org/10.1192/bjp.bp.111.107664

Berelson, B. (1952). Content Analysis in Communication Research. New York: Free Press.

Cohn, N. (1961). Understanding the Process of Adjustment to Disability. Journal of Rehabilitation, 27, 16-18.

Comprehensive Survey of Living Conditions (2016). Percentage Distribution of Major Causes (Top 3 Causes) of Long-Term Care by Care Requirement Level.

https://www.mhlw.go.jp/english/database/db-hss/cslc-tables.html

Duncan, P. W., Lai, S. M., \& Keighley, J. (2000). Defining Post-Stroke Recovery: Implications for Design and Interpretation of Drug Trials. Neuropharmacology, 39, 835-841. https://doi.org/10.1016/S0028-3908(00)00003-4

Folstein, M. F., Maiberger, R., \& McHugh, P. R. (1977). Mood Disorder as a Specific Complication of Stroke. Journal of Neurology, Neurosurgery \& Psychiatry, 40, 1018-1020. https://doi.org/10.1136/jnnp.40.10.1018

Jorgren, H. S., Nakayama, H., Raaschou, H. O., Vive-Larsen, J., Stoier, M., \& Olsen, T. S. (1995). Outcome and Time Course of Recovery in Stroke. Part II: Time Course of Recovery, the Copenhagen Stroke Study. Archives of Physical Medicine and Rehabilitation, 76, 406-412. https://doi.org/10.1016/S0003-9993(95)80568-0

Kawakami, N. (2016). Prevalence and Treatment-Seeking Behavior. 3. Prevalence of Mental Disability and Treatment-Seeking Behavior. Large-Scale Epidemiological Survey of the Prevalence of Mental Disability-World Mental Health Japan Survey Second (pp. 33-66). Ministry of Health, Labour and Welfare KAKENHI Grant-in-Aid for Scientific Research-Project on Countermeasures for Handicapped Persons.

http://wmhj2.jp/WMHJ2-2016R.pdf\#search=\%27\%E7\%97\%85\%E7\%8E\%87\%E3\%81\% 8A\%E3\%82\%88\%E3\%81\%B3\%E5\%8F\%97\%E8\%A8\%BA\%E8\%A1\%8C\%E5\%8B\%95+ \%EF\%BC\%93\%E7\%B2\%BE\%E7\%A5\%9E\%E9\%9A\%9C\%E5\%AE\%B3\%E7\%AD\%89\%E 3\%81\%AE\%E6\%9C\%89\%E7\%97\%85\%E7\%8E\%87\%E3\%81\%8A\%Е3\%82\%88\%E3\%81 \%B3\%E5\%8F\%97\%E8\%A8\%BA\%E8\%A1\%8C\%E5\%8B\%95\%EF\%BC\%8E\%27

Kessler, R. C., \& Bromet, E. J. (2013). The Epidemiology of Depression across Cultures. Annual Reviews Public Health, 34, 119-138. https://doi.org/10.1146/annurev-publhealth-031912-114409

Lipsey, J. R., Spencer, W. C., Rabins, P. V., \& Robinson, R. G. (1986). Phenomenological Comparison of Post Stroke Depression and Functional Depression. American Journal of Psychiatry, 143, 527-529. https://doi.org/10.1176/ajp.143.4.527

Marin, R. S. (1991). Apathy: A Neuropsymailhiatric Syndrome. The Journal of Neuropsychiatry and Clinical Neurosciences, 3, 243-254. https://doi.org/10.1176/jnp.3.3.243

Osada, M., Muraoka, K., \& Liu, M. (2007). Post-Stroke Depression-Diagnosis and Treatment. The Japanese Journal of Rehabilitation Medicine, 44, 177-188. https://doi.org/10.2490/ijrmc.44.177

Ostir, G. V., Berges, I. M., Ottenbacher, A., \& Ottenbacher, K. J. (2011). Patterns of Change in Depression after Stroke. Journal of the American Geriatrics Society, 59, 314-320. https://doi.org/10.1111/j.1532-5415.2010.03266.x

Starkstein, S. E., Fedoroff, J. P., Price, T. R., Leiguarda, R., \& Robinson, R. G. (1993). Apathy Following Cerebrovascular Lesions. Stroke, 24, 1625-1630. https://doi.org/10.1161/01.STR.24.11.1625

Tateno, A., \& Robinson, R. G. (2002). The Effect of Poststroke Depression on Recovery from Stroke. Psycogeriatorics, 2, 73-84. https://doi.org/10.1111/j.1479-8301.2002.tb00054.x

World Health Organization (1992). International Statistical Classification of Diseases and Related Health Problems (10th Revision). Geneva: WHO. 